\title{
DIGITAL TRANSFORMATION OF EDUCATIONAL INSTITUTIONS: CHALLENGES, OPPORTUNITIES AND NEEDS CAUSED BY THE COVID-19 PANDEMIC
}

\author{
Abílio Azevedo, FEUP - Faculdade de Engenharia da Universidade do Porto, \\ Patrícia Azevedo, ESTG / P. Porto, Portugal
}

\section{Abstract}

Educational institutions have invested in digital transformation, bringing new opportunities, however, also presenting challenges associated with this change. Recently, the Covid-19 outbreak accelerated this process, accentuating online learning in the educational process. The purpose of this article was to present an overview of the challenges and opportunities related to digital transformation of educational institutions and the needs caused by the Covid-19 pandemic. Consequently, to better define the subject, it was conducted a qualitative methodology of bibliographic review. Digital transformation requires a reorganization of educational institutions, not only in the academic curriculum but also in both networking and social ways. Efforts are needed to integrate students and teachers in this digital age since they require training, monitoring and support in both digital knowledge and digital security. Otherwise, there is the risk of disruptions and anguish occurrence in the transitioning process and most of the advances made may not be sustainable. Despite all the known advantages of implementing new technologies in learning, digital divide raises concerns about equity. A good internet connection and availability of equipment are essential to make teaching process uniform and fair. Covid-19 pandemic forced digital transformation and the abrupt change in routines and procedures has putted everyone under great strain, namely teachers. However, this forced change also brought positive aspects such as investment in technologies of the future, with numerous initiatives and learning models already in practice and which are here to stay, as the teaching methods will never be the same after such an impactful experience.

Keywords: Digital education, digital transformation, educational institutions, challenges, covid-19. 
Azevedo, A., \& Azevedo, $P$.

Digital Transformation of Educational Institutions: Challenges, Opportunities and Needs Caused by the Covid-19 Pandemic

\section{Introduction}

Modern schools face challenges posed by new technologies in terms of the implementation of Information and

Communications Technology (ICT) in the sustainability of management, research and teaching activities (Abad-Segura, González-Zamar, Luque-de la Rosa, \& Cevallos, 2020; Tomczyk, 2019). The commercialisation of higher education, for instance, and the need to reform the university as a social institution, have carried themselves into the digital age and manifest new tensions, being other challenges, such as discussions around digital accessibility of course materials and the consequent declining role of the university professor more technologically driven (Nguyen, 2018). Digital transformation is frequently used to indicate a set of mainly technological, cultural, organizational, social, creative, and managerial changes, however, it goes beyond the simple adoption of new technologies, making possible to provide services, supply goods, and live experiences, creating opportunities and impacting society, in a strategic and prioritized way (Gobble, 2018; Maltese, 2018). Recent developments in ICT have transformed the way individuals learn and the Internet, in particular, has made available a virtually unlimited number of sources of information (Pagani, Argentin, Gui, \& Stanca, 2016). Massive Open Online Courses (MOOCs) are seen as means through which educational institutions such as universities can become more globally inclusive, with the potential to enhance quality of life in developing countries (Nguyen, 2018). As a result, the learning process increasingly requires the ability to access, locate, extract, evaluate, organize and present digital information (Pagani, Argentin, Gui, \& Stanca, 2016). Still, as shown in many research settings, the use of technology in classrooms and schools is still often superficial and not meeting the potential of technology as envisioned by education reformers and researchers in the field (Niederhauser et al., 2018). The fact is that digital transformation is already here, however, it is not yet evenly distributed (Grajek, 2020). Before the outbreak of the COVID-19 pandemic, the world was dealing with the learning crisis, evidenced by high levels of learning poverty being the spread of the new coronavirus, among several disruptions to normal life, necessitated more than 160 countries to effect temporary closure of schools due to safety of their students and staff (Mhlanga \& Moloi, 2020; Rashid, Radzniwan, Rashid, Yaman, \& Mohamad, 2020). The World Bank estimates that 1.6 billion children and youth were left out of school and about $85 \%$ of learners were affected by the fact that educational institutions have suspended their face to face classes (Bran \& Grosseck, 2020; Mhlanga \& Moloi, 2020). Educational institutions had to quickly launch and adopt online learning platforms in the education sector during the pandemic and physical access, motivation, skills, and actual usage of digital technologies have created a digital divide to those various dimensions of ICT, being the phenomenon even wider in the 
context of developing countries (Mhlanga \& Moloi, 2020; Soomro, Kale, Curtis, Akcaoglu, $\&$ Bernstein, 2020). Therefore, to better define the subject, a qualitative methodology of bibliographic review was conducted.

\section{Digital transformation and new educational technologies}

\section{Digital transformation challenges for universities and colleges}

Even though it brings new opportunities, digital transformation also poses new challenges for Communication and information technology (IT) departments of universities bringing the need to provide detailed information about a variety of key assets to their users such as information about their students, employees, professors, and researchers, their publications and patents, the courses they teach, and the research projects they conduct (Maltese, 2018). Innovation includes a package of designed curriculum materials, assessment instruments, teacher professional development plan, suite of software tools, school administrative and technology infrastructure, and ways to promote the desired education change (Zhang \& Looi, 2011). A study by Xiao (2019), examined how the role of digitalization is framed in the strategic development plans of 75 top universities in China and demonstrated that digitalization as perceived by these universities features instrumentality (e-campus construction and application) and modernization (sustaining and efficiency innovations in teaching and learning), a situation also seen in other countries. Additionally, the authors reported that, on the other hand, there seems to be not enough incentive for them to use digital technologies to serve a wider community and to build technology-enhanced research capacity. There was also stated that scanty evidence of open, flexible, distributed, and disaggregated learning encouraged in these plans.

It is difficult for universities to present a complete, up-to-date, and consistent view of their key assets across the different digital communication channels and digital services employed since the usage of different IT systems since they consist in: institutional communication, library management, HR management, teaching and student support, research and technology transfer support, project management and fundraising, financial support, IT support, legal support, logistics, strategic planning, and many others (Maltese, 2018).

\section{Digital knowledge}

Library as open access digital publisher

Since the ascent of the World Wide Web over two decades ago, scholars, academicians, artists, and academic librarians have enjoyed progressively greater, more robust, and more effective access to digital scholarly research resources, permitting a more robust and more effective access to digital collections and tools (Bailey, 2017). The role of digital libraries is 
changing, making possible new services supporting the user's activities (Barbuti, Di Giorgio, \& Valentini, 2019). Over the last years, open access (OA movement or initiative), that promotes equal and open access to scholarly research resources, has grown and evolved to provide more equitable access for academicians, scholars, and artists beyond those in the developed, fiscally more endowed areas and institutions (Laakso et al., 2011). There are some basic common elements to successful initiatives towards digital knowledge that comprehend that the quality, usefulness and importance is verified for the participants, that the initiative leaders are realistic as to required and available resources (scanning capacity, OCR/optical character recognition tools) and that the shared sense of collaborative team-work is present avoiding and resolving troublesome issues, which are common in such initiatives (Bailey, 2017).

\section{Teachers' perspective about the use of information and communications technology}

A study by Sipilä (2014) investigated teachers' perceptions about how ICT is being incorporated into teaching and learning, the level of teachers' digital competence and what factors, in their opinions, might be delaying the use of ICT in schools. The findings indicated that teachers who have advanced ICT competence use ICT frequently in education and that the majority of teachers do not have the means or knowledge to fully use ICT in promoting learning. Additionally, according to teachers' opinions, students have a good possibility of and knowledge about how to use ICT in studying and learning and state that information literacy and information management should be taught to students, however, the idea of providing personal learning paths in studying and learning processes is less familiar to teachers. The authors state that there are still contradictions between the formal structure of educational institutions (national development processes, curriculum, teacher training) and daily classroom practices (teaching, studying, learning), needing theory and practice to come closer.

\section{Teachers' knowledge about digital safety}

Digital safety is a very important subject when it comes to digital literacy (DL) and it was an interest of study by Tomczyk (2019) that determined the level of digital literacy among teachers, narrowing the DL scope to the issue of the safe use of electronic media. The results showed an unsatisfactory level of knowledge and skills among teachers in some media-related aspects, being the teachers of technical subjects (including ICT) those with the best results, whereas natural science teachers scored the lowest. Age was not a determinant of ICT expertise since a low level of DL and safety skills prevailed in the group of teachers who recently began their career in education breaking the stereotype that young teachers have much more advanced DL than older teachers. 


\section{Digital competence and digital literacy and the impact of digital skills on educational outcomes}

An important aspect of digital literacy relates to the impact on academic performance. Pagani et al. (2016) studied the effects of digital literacy on educational outcomes by merging data from the Italian National Assessment in secondary schools with an original dataset on performance tests of Internet skills for tenth-grade students. The results indicated that informational digital skills had a positive and significant effect on academic performance, being also stronger for students in technical or vocational schools. Moreover, the results showed that students with lower reading academic performance are those who benefit more from digital literacy, while for math tests the authors found a u-shape relationship between digital skills and student achievement.

\section{Sustainability of educational technologies}

Another of the several challenges presented by the rise of technological advancements in educational institutions was the sustainability of management, research and teaching activities (Abad-Segura et al., 2020). As presented in (Niederhauser et al., 2018) work, there are multiple interacting factors that influence the change process, and challenges are often encountered when implementing curricular and pedagogical innovations that integrate technologies, which can be daunting. The ultimate goal is to integrate classroom technology use that is more meaningful, purposeful and relevant to students, however, when technology projects have been implemented successfully in educational practice and shown valuable impacts, sustainability within similar contexts is not guaranteed. The results built on the discussions of the EDUsum-mIT 2017 Thematic Working Group 9 (TWG9) showed that teachers in training still maintained positive pedagogical views developed during the collaborative project in teams in their program of preparation of teachers in training, being the most influential factor on teachers' transfer and continuous use of the innovation. Furthermore, it was shown that the second most influential factor affecting teachers' continued use of the ICT-based innovation was their learner characteristics being knowledge and skills related to ICT use the most critical learner characteristics reported. Ultimately, as a worth noting point by the authors was that the most beginning teachers reported having sufficient knowledge and skills, which was an indication of how well the preparatory program contributed to teachers' professional learning.

\section{Digital divide and equity in education}

Digital equity is a complex and multifaceted concept and participatory citizenship in the digital era involves the right to access and participate in higher education being a key civil rights issue of the modern world (Willems, Farley, \& Campbell, 2019). Access to 
information and communications technology empowers teachers and students serving as an invaluable tool in bridging the digital divide, by bringing people together in pursuit of knowledge, encouraging the experiment of new methodologies and paradigms, and, most importantly, by making the process of learning more democratic (Anthony \& Padmanabhan, 2010). The increasing reliance on e-learning presupposes ubiquitous connectivity, however, the reality remains that $42 \%$ of the world's population does not have access to the internet by a number of reasons, including poor investment in information and communication technology infrastructure in a particular country or different government spending priorities (Willems et al., 2019). Despite increasing educational equity, it is evident that the way digital technology is used today is (perhaps inadvertently) strengthening existing socio-economic inequalities (Macgilchrist, 2019).

A variety of studies investigate digital inequalities in educational institutions such as a work by Soomro et al. (2020) that used a 57-item Faculty's ICT Access (FICTA) scale to assess physical, motivational, skills, and usage levels of teachers of governmental and private sector. The results showed that having access to computers and the Internet in the office or campus lab appears to encourage the use of technologies to support primary professional responsibility. In addition, the digital gap between faculty of public-sector and private-sector universities was found to be more prominent at skills access in respect of the faculty's age and university type. The findings suggested that faculty's physical access to ICT at university, teachers' endogenous motivational access and their general usage access to ICT were the significant predictors of their instructional usage of ICT. Another study by Lembani, Gunter, Breines, and Dalu (2020) explored the nature of access to ICT and how that affects students' ability to access higher education in Africa. The results demonstrated that the spatialities of access to a computer and internet remains a challenge for inclusive open distance learning (ODL) since for students living in urban areas had a significantly different educational experience to students with poor ICT access in urban, peri-urban and rural areas.

\section{The Covid-19 pandemic paradigm}

\section{Digital education in disruptive times}

While universities are used to natural disasters like bushfires, earthquakes and tornados, health crises such as the Covid-19 pandemic are less expected and harder to deal with since the last major worldwide health crisis occurred 100 years ago with the 1918-1920 Spanish flu pandemic (Kraus et al., 2020). There is no known cure or treatment for Covid-19 at this moment, which has led to an unprecedented challenge for society due to the chaos and uncertainty it has created (Leung, Sharma, Adithipyangkul, \& Hosie, 2020). The impact of COVID-19 and the emergency online migration of university communities is undeniably 
huge, nevertheless, the world is only at the earliest of beginnings of recognizing and understanding those impacts on the role of academics and the future of global higher education, remaining many follow-up questions to pose (Watermeyer, Crick, Knight, \& Goodall, 2020).

\section{Teachers' perspectives and experiences during the Covid-19 pandemic}

The pandemic unprecedented damage to the educational system worldwide affected in a particular way teachers, who are the most critical intellectual resources of any schools, having to face various types of financial, physical, and mental struggles due to COVID-19 (Vu et al., 2020). In a work developed by (Code, Ralph, \& Forde, 2020), the authors explored the experiences of technology education (TE) teachers during the COVID-19 pandemic. Their results demonstrated that the majority of TE students do not have the required machinery and specialized equipment at home, though access to the appropriate tools and technologies forms an essential part of building knowledge, skills and attitudes in the area. Furthermore, TE teachers have found themselves at the cusp of a rapid change that is compelling them to re-think their worldview in both how they teach and how their students learn, necessitating their transformation as educators raising questions about the overall effectiveness of online learning approaches and TE's future and sustainability if offered completely online. Another study by Dong (2020), presented a series of challenges confronting both Chinese teachers and English-medium degree program software engineering Bangladeshi students for their online interactions who were forced to turn to online instruction for academic study. The results revealed that when it comes to students' engagement and participation in online class, all of teachers claimed that just half of students attended the class. Participants also pointed out that students play the most essential role in online courses having both positive and negative experiences towards online classes. Overall, at the initial time of online classes, students embraced a positive attitude towards online class simply because it was an interesting and new teaching style comparing with real class, and they also had much more freedom than before. On the other hand, later on, students faced negative feelings about online class since it brought some difficulties, such as the tedious teaching styles and uninteresting online contents, less interaction with teachers and classmates as well as unfamiliarity with online teaching applications. Rashid et al. (2020) studied the issues around medical teaching during the COVID-19 pandemic and described that internet connection was one of the main issues as lecturers and students still face internet stability problems. Other problems reported occurred due to the limited number of available computers, tablets and mobiles phone per family. It was also reported that many needed to take turns for online learning, which led to the adoption of asynchronous teaching learning method as usually preferred. The authors also mentioned the fact that this pandemic taught medical lecturers to adapt to 
changes and optimize the use of technology, not blocking completely the process of teaching and learning, however, more support is need to be given by educational institutions of higher learning such as technical and mental health assistance. A survey made by Watermeyer et al. (2020) to academics working in universities in the United Kingdom (UK), representing all the major disciplines and career hierarchy, showed academics bruised by their experience of emergency online transition and distrustful of a more prolonged and substantial embrace of digital pedagogies by their institutions. Respondents reported an history of professional dysfunction and disturbance, of inequality, exploitation and neglect; of confidence and trust abused and squandered; of disempowerment, displacement and marginalization; of self-concept on trial and in tatters; of vulnerability and helplessness; and of the loss of a much maligned past superseded by the perceived machinations of digital dystopia and threat of professional oblivion. The authors added that COVID-19 crisis appears to have dually quickened the inevitability of technological change or authority of technological determinism and supercharged a sense of existential panic among academics - many of whom appear now snared in the headlights of digital disruption due to significant dysfunctionality and disturbance to their pedagogical roles and their personal lives.

\section{Digital education from 2020 onwards}

\section{A new approach for digital education}

The development of "smart technologies", digital applications and educational resources of Massive Open Online Courses (MOOCs), Small Private Online Courses (SPOOCs) and several other is a factor of the global educational space transformations, grading the ways of education and its organization, especially in post-pandemic classrooms, in both mainstream and alternate school settings, that will be very different (Cherubini, 2020; Neborsky, Boguslavsky, Ladyzhets, \& Naumova, 2020).

There are no universal guidelines for how educational institutions can function during an educational disruption, and even more dilemmas arise when we think about the postCOVID19 period, yet, there are some efforts and solutions that emerge in an attempt to help a smooth and efficient digital transformation such as the RESET program suggested in a study by (Bran \& Grosseck, 2020). As the authors suggest, the practices and instruments used by colleagues in West University of Timisoara, Romania, when pressing the RESET button of the educational process, teachers/staff/decision makers might want to take these pillars into consideration: Stability (continue teaching your students), Safety (care for your students, and care for yourself, too) and Stay connected (communicate with your students, and be present whenever it is needed). The authors suggest that the model can be applied internationally, provided that educational institutions ask periodically for 
consistent feedback from their respective academic communities in order to make the optimal real-time decisions.

A study by Neborsky et al. (2020), from the vast number of trends that were prominently outlined in the global agenda for the development of universities and higher education, presented an analysis of key trends related to the digital transformation. Firstly, the authors highlighted Outside-the-Box strategies as a mandatory element of the educational policy of universities since digital platforms, including MOOC, provide three possibilities that are seen as values: distance, scale, and personalization, the same these components that made it possible to expand an act far beyond the classrooms, which was an additional opportunity in the context of COVID-19 pandemic. Secondly, Passport to Education, a pilot experiment at Boise State University that starts a new type of relationship between a student and a university, was pointed, being something like subscribing to online platforms like Amediateka or Netflix, costing USD 425 per month for six credit hours or USD 525 for nine in any of two online undergraduate programs being 30\% cheaper than full-time education. Thirdly, Network in Education, a growing trend as a new way of organizing social structures in the co-presence and in fourth place Blended Learning, an increasingly popular technology of traditional and online learning combination. In fifth place, the authors pointed Micro-Colleges, the MTI experiment that meets the needs of lifelong learning and opens up new horizons for higher education and Blockchain in Education with the capacity, imperceptibly changing the reality of higher education organization. Ultimately, VR-Technologies, Artificial Intelligence, Chatbots for Learning are also mentioned as new learning opportunities for the future.

\section{Conclusions}

The purpose of this article was to present an overview of the challenges and opportunities related to digital transformation of educational institutions and the needs caused by the Covid-19 pandemic. Digital transformation requires a reorganization of educational institutions, not only in terms of academic curriculum but also in both networking and social ways. Efforts are needed to integrate students and teachers in this digital age since, both, require training, monitoring and support in digital knowledge and digital security. Otherwise, there is the risk of disruptions and anguish occurrence in the transitioning process and most of the advances made may not be sustainable. Despite all the known advantages of implementing new technologies in learning, digital divide is a reality that cannot be ignored, raising concerns about equity, both for those who learn and for those who teach. A good internet connection and availability of equipment are essential to reduce the distance between the privileged and the disadvantaged, making the teaching process uniform and fair. Clearly highlighting the pre-existing problem of digital equity, 
the Covid-19 pandemic has accelerated digital transformation. The abrupt change in routines and procedures has put everyone under great strain, namely teachers. However, the forced change also brought positive aspects such as investment in technologies of the future, with numerous initiatives and learning models already in practice and which are here to stay, as the teaching methods will never be the same after such an impactful experience. This article will certainly serve to offer a contribution to the existing discussion on a topic that arouses great interest and attention, as it affects our daily lives in several ways.

\section{References}

Abad-Segura, E., González-Zamar, M. D., Luque-de la Rosa, A., \& Cevallos, M. B. M. (2020). Sustainability of educational technologies: An approach to augmented reality research. Sustainability (Switzerland), 12(10), 1-29.

https://doi.org/10.3390/su12104091

Anthony, J., \& Padmanabhan, S. (2010). Digital Divide and Equity in Education: A Rawlsian Analysis. Journal of Information Technology Case and Application Research, 12(4), 37-62. https://doi.org/10.1080/15228053.2010.10856195

Bailey, D. R. (2017). Creating digital knowledge: Library as open access digital publisher. College and Undergraduate Libraries, 24(2-4), 216-225.

https://doi.org/10.1080/10691316.2017.1323695

Barbuti, N., Di Giorgio, S., \& Valentini, A. (2019). The Project BIBLIO-Boosting Digital Skills and Competencies for Librarians in Europe: An Innovative Training Model for Creating Digital Librarian. International Information and Library Review, 51(4), 300304. https://doi.org/10.1080/10572317.2019.1669935

Bran, R. A., \& Grosseck, G. (2020). Press RESET: Digitalising Education in Disruptive Times. Revista Romaneasca Pentru Educatie Multidimensionala, 12(1Sup2), 39-48. https://doi.org/10.18662/rrem/12.1sup2/245

Cherubini, L. (2020). Education in the Post-Pandemic Era: Indigenous Children and Youth. International Indigenous Policy Journal, 11(3), 1-11. https://doi.org/10.18584/iipj.2020.11.3.10679

Dong, J. (2020). Online Learning and Teaching Experiences During the COVID-19 Pandemic: A Case Study of Bangladeshi Students Receiving China's Higher Education. English Linguistics Research, 9(2), 37. https://doi.org/10.5430/elr.v9n2p37

Gobble, M. M. (2018). Digital Strategy and Digital Transformation. Research-Technology Management, 61(5), 66-71. https://doi.org/10.1080/08956308.2018.1495969 
Kraus, S., Clauss, T., Breier, M., Gast, J., Zardini, A., \& Tiberius, V. (2020). The economics of COVID-19: initial empirical evidence on how family firms in five European countries cope with the corona crisis. International Journal of Entrepreneurial Behaviour and Research, 26(5), 1067-1092. https://doi.org/10.1108/IJEBR-04-20200214

Laakso, M., Welling, P., Bukvova, H., Nyman, L., Björk, B. C., \& Hedlund, T. (2011). The development of open access journal publishing from 1993 to 2009. PLOS ONE, 6(6). https://doi.org/10.1371/journal.pone.0020961

Lembani, R., Gunter, A., Breines, M., \& Dalu, M. T. B. (2020). The same course, different access: the digital divide between urban and rural distance education students in South Africa. Journal of Geography in Higher Education, 44(1), 70-84. https://doi.org/10.1080/03098265.2019.1694876

Leung, T. Y., Sharma, P., Adithipyangkul, P., \& Hosie, P. (2020). Gender equity and public health outcomes: The COVID19 experience. Journal of Business Research, 116, 193-198. https://doi.org/10.1016/j.jbusres.2020.05.031

Macgilchrist, F. (2019). Cruel optimism in edtech: when the digital data practices of educational technology providers inadvertently hinder educational equity. Learning, Media and Technology, 44(1), 77-86. https://doi.org/10.1080/17439884.2018.1556217

Maltese, V. (2018). Digital transformation challenges for universities: Ensuring information consistency across digital services. Cataloging and Classification Quarterly, 56(7), 592-606. https://doi.org/10.1080/01639374.2018.1504847

Mhlanga, D., \& Moloi, T. (2020). COVID-19 and the digital transformation of education: What are we learning on 4ir in South Africa? Education Sciences, 10(7), 1-11. https://doi.org/10.3390/educsci10070180

Neborsky, E. V., Boguslavsky, M. V., Ladyzhets, N. S., \& Naumova, T. A. (2020). Digital Transformation of Higher Education: International Trends. Proceedings of the International Scientific Conference "Digitalization of Education: History, Trends and Prospects” (DETP 2020), 393-398. https://doi.org/10.2991/assehr.k.200509.071

Nguyen, D. (2018). The university in a world of digital technologies: Tensions and challenges. Australasian Marketing Journal, 26(2), 79-82. https://doi.org/10.1016/j.ausmj.2018.05.012

Niederhauser, D. S., Howard, S. K., Voogt, J., Agyei, D. D., Laferriere, T., Tondeur, J., \& Cox, M. J. (2018). Sustainability and Scalability in Educational Technology Initiatives: Research-Informed Practice. Technology, Knowledge and Learning, 23(3), 507-523. https://doi.org/10.1007/s10758-018-9382-z 
Pagani, L., Argentin, G., Gui, M., \& Stanca, L. (2016). The impact of digital skills on educational outcomes: evidence from performance tests. Educational Studies, 42(2), 137-162. https://doi.org/10.1080/03055698.2016.1148588

Rashid, A. A., Radzniwan, M., Rashid, A., Yaman, M. N., \& Mohamad, I. (2020). Teaching Medicine Online During the COVID-19 Pandemic: A Malaysian Perspective. Bangladesh Journal of Medical Science, 19, 77-81. https://doi.org/10.3329/bjms.v19i0.48170.

Sipilä, K. (2014). Educational use of information and communications technology: Teachers' perspective. Technology, Pedagogy and Education, 23(2), 225-241. https://doi.org/10.1080/1475939X.2013.813407

Soomro, K. A., Kale, U., Curtis, R., Akcaoglu, M., \& Bernstein, M. (2020). Digital divide among higher education faculty. International Journal of Educational Technology in Higher Education, 17(1). https://doi.org/10.1186/s41239-02000191-5

Tomczyk, Ł. (2019). What Do Teachers Know About Digital Safety? Computers in the Schools, 36(3), 167-187. https://doi.org/10.1080/07380569.2019.1642728

Watermeyer, R., Crick, T., Knight, C., \& Goodall, J. (2020). COVID-19 and digital disruption in UK universities: afflictions and affordances of emergency online migration. Higher Education. https://doi.org/10.1007/s10734-020-00561-y

Willems, J., Farley, H., \& Campbell, C. (2019). The increasing significance of digital equity in higher education: An introduction to the Digital equity special issue. Australasian Journal of Educational Technology, 35(6), 1-8. https://doi.org/10.14742/ajet.5996

Xiao, J. (2019). Digital transformation in higher education: critiquing the five-year development plans (2016-2020) of 75 Chinese universities. Distance Education, 40(4), 515-533. https://doi.org/10.1080/01587919.2019.1680272

Zhang, B. H., \& Looi, C. K. (2011). Developing a sustainable education innovation for seamless learning. Procedia - Social and Behavioral Sciences, 15, 2148-2154. https://doi.org/10.1016/j.sbspro.2011.04.069 